\title{
A IMPORTÂNCIA DE PRÁTICAS DA JUSTIÇA RESTAURATIVA NO COMBATE AO TRÁFICO DE DROGAS.
}

\section{THE IMPORTANCE OF JUSTICE RESTORATIVE TO COMBAT DRUG TRAFFICKING}

\author{
Henrique Ribeiro Cardoso ${ }^{1}$ \\ Osvaldo Resende Neto ${ }^{2}$
}

\section{RESUMO}

Nas últimas décadas, tem-se questionado o modelo penal de justiça retributiva por não ter se demonstrado idôneo na prevenção e repressão da criminalidade brasileira. $\mathrm{O}$ aumento estrondoso da população carcerária, com o número de presos por tráfico de drogas, suscita uma série de políticas criminais acerca de formas alternativas eficazes, ou menos danosas, para o equacionamento do problema em detrimento do modelo clássico punitivo. A natureza mercantil do tráfico, ao mesmo tempo em que revela a importância para consumação do delito, abre as possibilidades para inserção de práticas restaurativas mais amplas, que vão além das permitidas legalmente.

Palavras-chaves: Tráfico de drogas. Justiça restaurativa. Usuário de drogas. Oferta e demanda. Superpopulação carcerária.

\begin{abstract}
Over the last few decades, the criminal model of retributive justice has been challenged for not being suitable for the prevention and repression of criminality in Brazil. The high incarceration rate has increased with the number of drug trafficking prisoners which leads to, consequently, a formulation of criminal policy on the standard punitive model rather effective alternative forms, or less harmful for solving the problem. Its commercial nature at the same time reveals the importance for the consummation of the crime opening the possibilities for insertion of the extensive restorative practices, which exceeds the legally allowed.
\end{abstract}

Keywords: Drug trafficking. Restorative Justice. Drug's user. Supply and demand. Prison superpopulation.

\footnotetext{
${ }^{1}$ Doutor em Direito (UGF/Rio) com Pós-doutorado em Democracia e Direitos Humanos (IGC/Coimbra). Professor dos Programas de Pós-graduação da Universidade Federal de Sergipe e da Universidade Tiradentes. Promotor de Justiça.

${ }^{2}$ Mestrando no Programa de Pós-Graduação da Universidade Federal de Sergipe. Especialista em Segurança Pública pela Universidade Federal de Sergipe e Gestão Estratégica em Segurança Pública pelo ISEIB/MG. Delegado de Polícia.
} 


\section{INTRODUÇÃO}

Nas últimas décadas, tem-se debatido criticamente o modelo penal de justiça retributiva, em especial por não ter se demonstrado um paradigma idôneo na prevenção e repressão adequada de infrações penais, seja porque não se tem vislumbrado a redução dos índices de criminalidade, seja porque não tem se revelado como método suficiente ou compatível com a ressocialização do autor da infração penal.

No Brasil, o aumento estrondoso da população carcerária - dados oficiais apontam um crescimento de $67 \%$ entre os anos de 2004 e $2014^{3}$ - tem suscitado uma série de questionamentos jurídicos, sociais e de política criminal acerca do modelo clássico punitivo adotado pelo país, bem como a busca de formas alternativas eficazes, ou menos danosas, para o equacionamento da criminalidade. Nessa conjectura, tem-se erguido com mais veemência as vozes defensoras do modelo de justiça restaurativa, cujos postulados vêm sendo inseridos paulatinamente na cultura jurídica brasileira, consubstanciada na visão de completa inversão no papel do Estado e da sociedade civil na persecução da solução do litígio penal. A infração passa a ser analisada e tratada sob uma ótica completamente diferente de outrora. Tomando emprestado as palavras que intitulam a obra do professor Howard Zehr (2008), é um trocar de lentes.

Historicamente, o modelo primário vigente no seio social a vingança privada, a partir do fim da Idade Média, foi tomado para si pelo poder público sob a rubrica jus puniendi. Contudo, "Esse processo não aconteceu através da tomada direta e súbita de uma ampla gama de processos pelos Estado. Ao contrário, os representantes deste foram se insinuando gradualmente no processo. Começando como investigador, o Estado paulatinamente se tornou acusador. ” (ZEHR, 2008, p. 104). Esclareça-se, desde logo, que não se objetiva aqui questionar a legitimidade do poder de punir estatal, porém é notória a falibilidade do sistema sua implementação. Assim, diante dessa falibilidade, tem ganhado força o modelo de justiça restaurativa em boa parte da seara jurídica. Essa tendência mundial é acompanhada da flexibilização do rigor punitivo direcionado ao autor do delito ou contravenção penal.

Dentro da discussão da falibilidade do sistema criminal brasileiro, chama atenção o fato

\footnotetext{
3 A taxa de aprisionamento no Brasil aumentou 67\% entre 2004 e 2014, segundo Levantamento Nacional de Informações Penitenciárias. Conforme mostra o estudo, o ritmo de encarceramento no país segue a tendência contrária de lugares com as maiores populações prisionais do mundo. "É importante ressaltar os danos que a prisão acarreta não apenas para as pessoas encarceradas, como também para seu círculo familiar", afirmou o diretor-geral do Departamento Penitenciário Nacional (Depen), Renato De Vitto. De acordo com o balanço, a população penitenciária brasileira chegou a 622.202 pessoas em dezembro de 2014, com a maioria formada por jovens, negros e de baixa escolaridade. carceraria-brasileira-ja-e-uma-das-maiores-do-mundo-diz-jus.shtml Acesso em 12 de julho de 2016.
} 
de que o tráfico de entorpecentes é o delito com maior índice de incidência na superpopulação carcerária do país - $28 \%$ em um universo de presos provisórios e condenados. Os mais de seiscentos e vinte e dois mil detentos constituem o quarto maior número de presos do planeta, ficando atrás apenas dos Estados Unidos, China e Rússia ${ }^{4}$. Essa situação é ainda mais alarmante no público feminino, cujos dados coletados por revelam que o tráfico de drogas corresponde a $65 \%$ do crime objeto das prisões ${ }^{5}$.

No Brasil, especificamente na situação da prevenção e repressão dos crimes relacionados ao tráfico de drogas e congêneres, há quem afirme que a Lei n. 11.343 de 2006, em substituição aos diplomas anteriores, Lei n. 6.368 de 1976 e Lei n. 10.409 de 2002, trouxe um tratamento restaurativo aos delitos relacionados ao consumidor de substâncias entorpecentes. Segundo seus defensores, embora o modelo continue proibicionista, “a Justiça Retributiva, baseada no castigo, é substituída pela Justiça Restaurativa, cujo objetivo maior é a ressocialização por meio de penas alternativas" (DUARTE; DALBOSCO; ANDRADE, 2011, p. 18).

Ademais, tem-se observado, no decorrer dos últimos anos, que o legislador, os tribunais e a doutrina nacionais têm adotado um tratamento mais rigoroso para o traficante e, concomitantemente, vem procedendo de forma mais branda com os indivíduos considerados usuários e/ou dependentes de drogas ilícitas. Basta visualizar que a nova lei de entorpecentes aumentou as penas cominadas para os ditos traficantes e, simultaneamente, trouxe alternativas à pena de privativa de liberdade para o consumidor de drogas, além de restringir o conceito legal de traficante, de modo que abarcou um número menor de condutas humanas, isto é, ações ou omissões antes poderiam ser equiparadas ao tráfico, para parte do mundo jurídico, passaram para outro patamar legal, a exemplo do "uso compartilhado".

É nesse cenário que este trabalho irá se desenvolver, qual seja: se o aumento do rigor sancionador ao traficante de drogas somado com a crescente tolerância do seu consumo temse demonstrado uma incorporação eficaz, ainda que tímida, do modelo de justiça restaurativa no Brasil.

O exame da hipótese aqui proposta, é antecedida da exposição das principais

\footnotetext{
${ }^{4}$ Ainda de acordo com o último relatório do Levantamento Nacional de Informações Penitenciárias, do mês de dezembro de 2014 o Brasil possui com a quarta maior população penitenciária do mundo, perdendo somente para os Estados Unidos, a China e a Rússia. Em relação ao tipo de infrações penais, 28\% dos detentos respondiam ou foram condenados por crime de tráfico de drogas, $25 \%$ por roubo, $13 \%$ por furto e $10 \%$ por homicídio. Disponível em http://www.justica.gov.br/noticias/populacao-carceraria-brasileira-chega-a-mais-de622-mil-detentos Acesso em 22 de setembro de 2016.

${ }^{5}$ O Encontro Nacional sobre o Encarceramento Feminino asseverou que das 15.263 mulheres que passaram, nos últimos cinco anos, a fazer parte da população carcerária brasileira, 9.989 (65\%) foram acusadas de tráfico de drogas. Disponível em https://www.senado.gov.br/noticias/Jornal/emdiscussao/dependencia-quimica/crackchama-a-atencao-para-dependencia-quimica/populacao-carceraria.aspx Acessado em 22 de setembro de 2016.
} 
mudanças legislativas advindas com a Lei n. 11.343/2006 no tocante ao recrudescimento do tratamento conferido ao traficante, em contrapartida das normais mais benevolentes que regem a situação jurídica do consumidor/usuário de drogas. Em seguida, passa-se para análise de dados estatísticos e, na sequência, para um sucinto estudo da correspondência das normas do referido diploma com os postulados da justiça restaurativa. Adentra-se no tema interdisciplinar da relação comercial existente no tráfico e, ao final, é proposta uma conclusão de cunho reflexivo sobre a temática abordada.

Para tanto, foram exploradas estatísticas oficiais das Nações Unidas, da Universidade Federal de São Paulo e do Estado de Sergipe, consulta a órgãos policiais especializados na repressão ao tráfico de drogas, exame de doutrina nacional, decisões judiciais e consulta à legislação vigente e revogada sobre o tema.

Passa-se, no item seguinte, a retratar as principais alterações legislativas advindas com a Lei n. 11.343/2006 relacionadas com o tema objeto deste artigo.

\section{INOVAÇÕES JURÍDICAS REFERENTES AO TRAFICANTE E O CONSUMIDOR DE DROGAS COM O ADVENTO DA NOVA LEI DE DROGAS}

No dia 23 de agosto de 2006, foi publicada a Lei n. 11.343, a nova Lei de Drogas, revogando expressamente a Lei n. 6.368/1976 e a Lei n. 10.409/2002, sepultando, assim, anterior discussão acerca de qual procedimento ritualístico deveria ser aplicado aos crimes em debate, posto que, como se sabe, a Lei n. 10.409/2002 tinha sido publicada com sua parte criminal vetada.

São várias as inovações trazidas pela Lei n. 11.343/2006, destacando-se a parte criminal, que além de preservar boa parte das condutas previstas na Lei n. 6.368/1976, criou novos tipos penais, adotando uma política criminal mais complacente em relação ao usuário e/ou dependente de drogas ilícitas, inclusive com punições alternativas à pena privativa de liberdade, enquanto que para as condutas de tráfico acabou se revelando mais gravosa do que a legislação anterior (LIMA, 2015, p. 741).

Dentre outras mudanças, menciona-se que, na vigência da Lei n. 6.368/1976, não havia previsão das condutas semear/cultivar/colher plantas destinadas à preparação de pequenas quantidades de entorpecentes para uso próprio. Assim, sobre o assunto, surgiram, na época, três posicionamentos: 1) que a conduta seria enquadrada no art. 16, equiparando-se ao consumidor de drogas, valendo-se de analogia in bonam partem, corrente que, até então, 
era majoritária nos tribunais; 2) o fato seria enquadrado no art. $12, \S 1^{\circ}$, inciso II, da Lei n. 6.368/1976, equiparando-se ao traficante; e 3) o fato seria atípico, pois o plantio para uso próprio não estava previsto em lugar nenhum, nem como figura equiparada ao art. 12, nem como figura analógica ao art. 16 (LIMA, 2015, p. 719-720).

Atualmente, a discussão perdeu sentido com a Lei n. 11.343/2006, uma vez que as condutas supramencionadas foram previstas expressamente no parágrafo $1^{\circ}$, do art. 28 , tratando-se, como uma forma equiparada ao do consumo.

Prosseguindo, explicita-se que as situações denominadas pela doutrina como "uso compartilhado", que, na vigência da Lei n. 6.368/1976, caracterizava para parte da doutrina e jurisprudência como conduta de tráfico, passaram, com a nova Lei de Drogas, desde que atendidos os requisitos legais ${ }^{6}$, a ter um tratamento bastante diferenciado, com normas mais brandas, inclusive tendo status de crime de menor potencial ofensivo (MARCÃO, 2014).

Após o advento da Lei n. 8.072/1990, Lei de Crimes Hediondos, houve grande polêmica se o art. $8^{\circ}$ deste diploma havia revogado o art. 14 da Lei n 6.368/1976, referente a associação criminosa, vez que diminuiu a pena cominada. Prevalecia o entendimento de que continuava vigente o art. 14 da Lei n. 6.368/1976, porém, a pena a ser aplicada deveria ser a do art. $8^{\circ}$ da Lei de Crimes Hediondos, em uma técnica interpretativa de combinação de leis para beneficiar o réu. Com a redação do art. 35 da nova Lei de Drogas a discussão perdeu sentido, pois se trata de norma posterior e que trata do mesmo tema, não sendo mais necessária a combinação de leis. Contudo, nota-se que a pena abstrata deste dispositivo é maior do que a prevista no art. $8^{\circ}$ da Lei de Crimes Hediondos. De conseguinte, é uma outra hipótese de punição mais rigorosa aos traficantes envolvidos em associação criminosa (LIMA, 2015, p. 776).

Houve também a criação de alguns tipos penais, a exemplo das infrações penais previstas no art. 36 (financiamento do tráfico), art. 37 (informante do tráfico) e art. 39 (condução de embarcação ou aeronave sob o efeito de entorpecentes) da Lei n. 11.343/2006, anteriormente não previstos na Lei n. 6.368/1976.

Nesse contexto, além das já conhecidas modalidades de tráfico, então previstas na revogada Lei n. 6.368/1976, a Lei n. 11.343/2006 criou novos tipos que poderiam, em algumas situações, ser tipificados nos dispositivos revogados, a depender das circunstâncias

\footnotetext{
${ }^{6}$ Somente o oferecimento de droga eventual e sem objetivo de lucro, a pessoa de seu relacionamento, para juntos a consumirem é que autoriza o reconhecimento da conformação típica mais branda. Ausente um dos requisitos, a conduta se ajustará ao tipo de tráfico fundamental, conforme o art. 33, caput.
} 
dos fatos concretos. De fato, as citadas condutas não se inserem no tipo penal específico do tráfico de drogas da nova lei (art. 33, caput) e nem nas suas formas assemelhadas ou equiparadas (art. 33, § $1^{\circ}$ ), configurando modalidades especiais que passaram a ser consideradas infrações penais autônomas.

Vislumbra-se ainda o aumento da pena cominada para as situações típicas de tráfico de drogas (art. 33, caput e $\S 1^{\circ}$ ). A lei posterior, hoje em vigor, acresceu à pena prevista de prisão mínima em dois anos e aumentou consideravelmente a pena de multa ${ }^{7}$. Isso sem mencionar as situações que agravam a pena que estão previstas em seu art. 40.

Não é só. A nova lei descriminalizou o delito anteriormente previsto no art. $12, \S 2^{\circ}$, inciso II, da Lei n. 6.368/1976, nas ocasiões em que o indivíduo cede o local para que terceiro realize nele o uso de drogas. Apenas persistiu o crime quando o indivíduo ceder o local para que terceiro possa realizar o tráfico de entorpecentes. "A nova redação não fez referência à utilização 'para uso indevido', ocorrendo abolitio criminis em relação a tal conduta" (MARCÃO, 2014, p. 122). Novamente, constata- se uma benevolência para situações em que envolvam o consumo, diferentemente do tráfico.

Portanto, o advento da nova Lei de Tóxicos, como foi abordado, trouxe: 1) novas infrações penais autônomas; 2) penas alternativas à privativa de liberdade para o usuário e/ou dependente; 3) expressamente tratamento legal semelhante ao usuário ou dependente para os delitos de "uso compartilhado" e de semeio/cultivo/colheita para consumo; 4) aumento da pena abstratamente cominada para as situações de associação criminosa; 5) exasperação da pena privativa de liberdade mínima e de multa para o crime de tráfico e figuras equiparadas; e 6) abolitio criminis para a cessão de uso de local para que terceiro consuma narcóticos.

Nesse sentido, é inequívoca a tendência do legislador, seguida pela doutrina e jurisprudência nacionais, em conferir um tratamento mais rigoroso ao traficante e, ao mesmo tempo, em tratar o consumidor de drogas de forma mais moderada. Optou-se, dessa forma, por seguir a tendência restaurativa de combate às drogas, visando, sobretudo, instaurar uma nova política preventiva, direcionando o usuário e/ou dependente para atividades assistenciais.

Essa flexibilização legislativa advinda com a nova Lei de Tóxicos criou grandes debates e divergências na seara jurídica, gerando, inclusive questionamentos sobre a

\footnotetext{
${ }^{7}$ A pena cominada ao delito de tráfico no art. 12 da Lei n. 6.368/1976 era de reclusão, de 3 a 15 anos, e pagamento de 50 a 360 dias-multa. $\mathrm{O}$ art. 33 da Lei n. 11.343/2006 prevê pena de reclusão de 5 a 15 anos e pagamento de 500 a 1.500 dias-multa. Nota-se o aumento da pena mínima comida para a prisão em 2 anos, bem
} 
descriminalização do porte de drogas para consumo próprio.

Defendendo o abolitio criminis, cita-se Gomes et al. (2006, p. 109), para quem o legislador descriminalizou o porte de drogas para consumo, dedução concebida a partir do art. $1^{\circ}$ da Lei de Introdução do Código Penal, que define crime como a infração penal que a lei preveja pena de reclusão ou detenção e/ou multa; como contravenção a infração penal que a lei comine prisão simples e/ou multa.

Entrementes, a doutrina pátria e o Supremo Tribunal Federal, em diversos julgados, a exemplo do RE 430.105/RJ, pacificou o debate afirmando que se trata de hipótese de despenalização e não de descriminalização: "a jurisprudência desta Corte assentou o entendimento de que a conduta de portar droga para o consumo pessoal, prevista no art. 28 da Lei n. 11.343/2006, não perdeu seu caráter criminoso" ${ }^{\text {. }}$.

As discordâncias, acima mencionadas, no tocante a descriminalização ou a penalização do porte da droga para consumo surgem em um processo natural e esperado, que Barroso (2015, p. 349) denominada de desacordos morais razoáveis:

\begin{abstract}
No mundo contemporâneo, nas sociedades plurais e complexas em que nós vivemos, pessoas esclarecidas e bem intencionadas pensam de maneira diferente acerca de temas moralmente controvertidos. Não é difícil de comprovar e ilustrar o argumento com situações envolvendo (a) eutanásia e suicídio assistido, isto é, a existência ou não de um direito à morte digna; (b) a questão da recusa de transfusão de sangue por pessoas adeptas da religião Testemunhas de Jeová; e (c) o debate sobre a descriminalização das drogas leves.
\end{abstract}

Adentrando no entendimento de que art. 28 da Lei de Drogas é caso de despenalização e não de descriminalização, imprescindível verificar a possibilidade da aplicação do princípio da insignificância nas situações em que o consumidor estiver portando pequenas quantidades de entorpecentes. Nucci (2008, p. 305), entre outros nomes renomados, leciona no sentido da impossibilidade da aplicação do princípio da insignificância ou da bagatela, dentro do contexto jurídico de como o crime de posse de entorpecente para consumo próprio vem disciplinado na legislação vigente.

O Supremo Tribunal Federal chegou a decidir pela possibilidade de aplicação do princípio da insignificância nas infrações penais de posse de narcóticos para uso, no julgamento do Habeas Corpus 110.475/SC, no ano de 2012, embora não reflita o

como o incremento de 10 vezes para a mínima de multa e de mais de 4 vezes para a máxima.

${ }^{8}$ O Supremo Tribunal Federal reafirma o caráter proibicista do crime de porte para uso adotado pela Lei $n$. 11.343/2006, dirimindo dúvidas sobre a natureza penal de suas sanções. STF, AI 741.072 AgR/RJ, $1^{\text {a }}$ T., rel. Min. Dias Toffoli, j. 22/2/2011, DJe de 25/5/2011. 
entendimento majoritário da Corte. O Superior Tribunal de Justiça já havia decidido bem antes nesse mesmo pensamento no RHC 7.252/MG, no ano de 1998:

\begin{abstract}
Todo crime, além da conduta, tem resultado. No caso, prevenir a saúde, o bemestar físico do paciente para não sofrer dependência física ou psíquica, à qual a lei se refere. Tratando-se, no caso concreto, de um cigarro de maconha e não havendo informação de esse comportamento traduzir repetição, sequência de outros da mesma natureza, é evidente que a pequena quantidade não é bastante para causar o evento. Se houve a conduta, não houve, entretanto, o resultado relativamente relevante. É importante demonstrar se a substância trazia potencial para afetar o bem juridicamente tutelado.
\end{abstract}

De conseguinte, ainda dentre aqueles que defendem que a existência do crime supramencionado diante da despenalização, há quem se utilize do princípio da insignificância em determinadas circunstâncias fáticas, operacionalizando o abolitio criminis. Mais uma vez, observam-se decisões judiciais que tendem a flexibilizar as normas sancionadoras do porte de drogas para o consumo.

Acontece que o exame minucioso e prolongado acerca das divergências filosóficas e jurídicas da punição prevista para as situações de porte de drogas para consumo próprio, excede os limites do objeto deste trabalho, o qual está voltado para reflexão das consequências práticas desse novo tratamento diferenciado dado ao traficante e ao usuário e/ou dependente de entorpecentes, qual seja: recrudescer as normas que recaem sobre o traficante na medida em que se flexibiliza medidas punitivas ao consumidor de tóxicos revela a adoção para um modelo de justiça restaurativa para este.

Até o presente momento, discorreu-se sobre as inovações legais, os entendimentos doutrinários e jurisprudenciais relativos ao comércio ilícito de entorpecentes, em especial os crimes e as sanções que se direcionam ao traficante e ao consumidor usuário. A partir de agora, passar-se-á à exposição e análise de dados estatísticos relacionados ao crime de tráfico de substâncias entorpecentes, visto que são através de tais informações que são questionadas a eventual falibilidade do modelo de repressão ao tráfico.

\title{
2 A EVOLUÇÃO DO TRÁFICO DE DROGAS EM DADOS ESTATÍSTICOS
}

Uma das grandes dificuldades em trabalhos científicos do país é o acesso a dados estatísticos verdadeiros, mormente quando provenientes de arquivos estatais, aqui em sua acepção ampla, contemplam a administração pública direta e indireta em suas diversas entidades. Podem-se destacar, dentre outros, quatro fatores básicos que ocasionam esse 
obstáculo ao estudo científico: 1) preocupação apenas recente do poder público em trabalhar com armazenamento de dados estatísticos e suas projeções; 2) a utilização de métodos não eficazes na coleta desses números, a exemplo da ausência de centralização de informações; 3) o incômodo que dados negativos se tornem de conhecimento do público, prejudicando interesses pessoais, político-partidários e eleitoreiros de gestores; e 4) o comércio de drogas é atividade ilegal, desenvolvida longe do controle estatal, sendo que o poder público toma ciência apenas de uma parcela da realidade efetiva, não podendo em se falar em números precisos e condizentes com a realidade, mas tão somente em projeções e estimativas.

A nova Lei de Tóxicos confere atenção peculiar aos dados estatísticos nacionais de repressão ao tráfico de drogas, os quais, segundo dispõe o seu art. 17, integrarão o sistema de informações do Poder Executivo. No entanto, Marcão (2014, P. 36) critica o conteúdo restritivo do art. 17 da Lei n. 11.343/2006 afirmando que "se refere apenas aos dados estatísticos nacionais de repressão ao tráfico ilícito de drogas, quando deveria ter alcance mais dilatado e abranger também os dados estatísticos referentes ao crime de porte de drogas para consumo pessoal".

Mesmo com todos esses empecilhos, é inquestionável que o acesso a tais informações está sendo otimizada, embora não na velocidade e na forma ideais condizentes com o mundo globalizado, em plena era da informatização digital. Ainda que precários, os dados estatísticos existentes já fornecem um parâmetro, possibilitando a produção de conhecimento e, consequentemente, estudos voltados para o tema, nas suas diversas finalidades (prevenção, repressão, descriminalização etc.). Marcão (2014, p. 36) afirma que “constituem importantes medidas de prevenção, orientadoras de políticas públicas direcionadas e mais exitosas, porquanto baseadas em dados concretos identificadores de cada realidade de que se busca cuidar".

Uma das informações obtidas foi o levantamento quantitativo de apreensões de substâncias entorpecentes realizadas na grande Aracaju, entre os anos de 2009 à 2012. No primeiro ano analisado, a quantidade de droga apreendida ficou em torno de $296 \mathrm{~kg}$. No ano seguinte, saltou para 587kg. Em 2011, o número sofreu poucas alterações. No último ano tido como parâmetro, o volume ascendeu para mais de $800 \mathrm{~kg}^{9}$.

Registra-se ainda que a estrutura policial (número de efetivo humano, armamento, recursos tecnológicos etc.) utilizada no combate ao tráfico de drogas foi praticamente a

\footnotetext{
${ }^{9}$ Informação fornecida pelo Departamento de Narcóticos do Estado de Sergipe, relacionada a área territorial da grande Aracaju, compreendendo as Cidades de Aracaju, Nossa Senhora do Socorro, São Cristóvão e Barra dos
} 
mesma durante esse período, sendo uma constante ${ }^{10}$. Nesse diapasão, vislumbra-se que, mesmo mantendo a estrutura estatal de enfrentamento ao tráfico de drogas como uma constante, houve, em termos brutos, um crescimento significativo do volume de apreensões de narcóticos durante o período e região tomados como base para estudo.

O número de homens e mulheres presos pelo crime de tráfico de drogas em 2009 foi de 266. No ano posterior, cresceu para 391. No subsequente, foi de 386. Em 2012, contabilizou 376 presos. Os dados expõem a tendência de apenas um leve aumento do número de prisões pelo delito de tráfico de drogas no território da grande Aracaju entre os anos de 2009 e 2012.

A conjugação das informações coletadas revela que o crescimento do número de drogas apreendidas está bem superior ao crescimento de pessoas presas por tráfico, de modo que pode levar a hipótese de que as pessoas envolvidas com o comércio ilícito de narcóticos estão cada vez trabalhando com maiores quantidades de entorpecentes, em Sergipe, ao menos, durante o período e na região objetos de exame.

Mais recentemente, o Estado de Sergipe divulgou um crescimento de 57,6\% de substâncias entorpecentes apreendidas entre os anos de 2015 e 2016, antes mesmo do fechamento deste último período ${ }^{11}$.

As informações obtidas não conduzem a conclusões fechadas e absolutas, todavia servem como parâmetros, que podem ser considerados em pesquisas, em formulação de políticas públicas etc.

Passada a análise dos dados estatísticos oficiais fornecidos pelo Estado de Sergipe, no item seguinte serão explorados a relação da flexibilização punitiva para com o consumidor de narcóticos com as práticas restaurativas.

\section{MODELO DE JUSTIÇA RESTAURATIVA: ALÉM DA FLEXIBILIZAÇÃO}

Um passo aparentemente simplório, porém fundamental, para o sucesso das práticas restaurativas consiste em mudar a concepção de que o crime é fruto de uma anomalia nas relações sociais e que, em razão disso, deve ser expurgado. Assim, muito mais do que uma contradição, o crime é algo esperado e normal no seio das tão complexas relações humanas. Sobre o tema, o professor John Paul Lederach (2012, p. 37) ensina que "os conflitos

Coqueiros. Os dados relativos aos anos posteriores encontravam-se imprecisos e/ou incompletos. ${ }^{10} \mathrm{Id}$. 
acontecem. Sua presença nos relacionamentos humanos é normal e perene. E mudanças são inevitáveis." Ainda mais em se tratando de situações de posse para consumo de drogas, em que o sujeito não consegue enxergar a potencial lesividade de sua ação a outrem ${ }^{12}$. Ao contrário, concebe como, no máximo, uma autolesão, fato atípico no Direito Penal brasileiro.

Uma vez concebido como algo típico das relações sociais, a doutrina da transformação de conflitos prega que o crime, assim como outros conflitos, pode e deve ser visto como uma oportunidade de mudanças pessoais e sociais, atuando como mola propulsora do desenvolvimento humano, na medida em que pressupõe a necessidade de auto responsabilização do agente transgressor. Ao invés de simplesmente ser responsabilizado, as práticas restaurativas atuam na conscientização do senso de responsabilidade do sujeito infrator, que tem se demonstrado medida mais eficaz socialmente, em especial na reeducação e prevenção de novos conflitos.

O modelo retributivo, focado na responsabilização, não permite de forma efetiva na tomada de consciência do autor do fato, isto é, na sua sensibilização de que agiu erroneamente prejudicando terceiros. No caso tido como paradigma, expondo a saúde de outros indivíduos. Nesse ponto, Howard Zehr (p. 27, 2012) leciona:

\begin{abstract}
O sistema de justiça penal se preocupa com responsabilizar os ofensores, mas isto não significa garantir que recebam a punição que merecem. $O$ processo dificilmente estimula o ofensor a compreender as consequências de seus atos ou desenvolver empatia em relação à vítima. Pelo contrário, o jogo adversarial exige que o ofensor defenda os próprios interesses. O ofensor é desestimulado a reconhecer sua responsabilidade e tem poucas oportunidades de agir de modo responsável concretamente.
\end{abstract}

A inexistência de uma vítima em concreto nas situações que envolvem os delitos da Lei de Tóxicos não pode ser um empecilho para a utilização de práticas de autoconscientização do problema pessoal e social. Até porque esse tipo de delito, embora não aponte para uma determinada vítima, todo contexto da sua execução produz diversas vítimas, que se entram relacionadas direta ou indiretamente com o crime.

Nota-se que o próprio art. 19 do referido diploma legal, ao tratar da prevenção do uso indevido de drogas, versa expressamente, em seu inciso III, que as atividades devem observar os princípios e diretrizes voltados para o fortalecimento da autonomia e da responsabilidade individual em relação ao uso indevido de drogas. Nesse contexto, não só é

${ }^{11}$ Id.

${ }^{12}$ É prudente registrar que essas faixas que acobertam a visão dos agentes do art. 28 da Lei n. 11.343/2006 
possível como também é conveniente e salutar a utilização de práticas circulares dos indivíduos envolvidos não só no art. 28 , mas também nos delitos relacionados ao crime de tráfico, vez que os círculos estão intimamente ligados com a construção de autoconscientização e buscas de alternativas saudáveis para o atendimento das necessidades.

Reunir pessoas com visões e experiências diferentes sobre o tema, em um mesmo ambiente circular, com indivíduos que já passaram por situações similares e superaram, órgãos de controle e fiscalização e, especialmente, vítimas e familiares que já tenham sofridos os efeitos danosos produzidos pelo tráfico de drogas. Cada um podendo expor seu ponto de vista e questionar o outro em um patamar de igualdade, sem receio de represálias. Uma prática efetivamente restaurativa, que não se encontra óbice legal, e que pode ser implementada. Segundo Carolyn Boyes-Watson e Kay Pranis (p.35, 2011):

\begin{abstract}
O círculo é um processo estruturado para organizar a comunicação em grupo, a construção de relacionamentos, tomada de decisões e resoluções de conflitos de forma eficiente. $\mathrm{O}$ processo cria um espaço à parte de nossos modos de estarmos juntos. O círculo incorpora e nutre uma filosofia de relacionamento e de interconectividade que pode nos guiar em todas as circunstâncias - dentro do círculo e fora dele.
\end{abstract}

De tudo o que foi dito, percebe-se que o modelo proibicionista persiste, mas, indubitavelmente, houve uma mudança de foco no tratamento jurídico dado ao usuário de drogas, com a introdução de normas mais brandas pela Lei n. 11.343/2006, que veio acompanhada por uma nova visão doutrinária e jurisprudencial, como bem assevera Renato Brasileiro de Lima (p. 701, 2015):

$\mathrm{O}$ art. $1^{\circ}$ da Lei $\mathrm{n}^{\circ} 11.343 / 06$ deixa claro que o principal objetivo da Lei de Drogas é conferir tratamento jurídico diverso ao usuário e ao traficante de drogas. Sob a premissa de que a pena privativa de liberdade em nada contribui para o problema social do uso indevido de drogas, o qual deve ser encarado como um problema de saúde pública - e não " de polícia" -, a Lei n ${ }^{\circ} 11$.343/06 inovou em relação à legislação pretérita, abolindo a possibilidade de aplicação de tal espécie de pena ao crime de porte de drogas para consumo pessoal.

Contudo, como foi apontado pelos dados estatísticos revelados, ao menos aparentemente, o tratamento dispare dado aos sujeitos da relação conflituosa aqui em debate não se tem demonstrado eficaz. Suscita-se, nesta oportunidade, a dúvida se essa diferenciação legal não nega a própria natureza da relação humana bilateral do comércio.

ocultam fatos danosos e extremamente graves, tais como corrupção, tráfico de armas, homicídios, roubos etc. 
Adentrando no tema, serão expostos alguns aspectos não jurídicos do comércio ilícito de drogas, mais precisamente a sua natureza mercantil.

\title{
4 RELAÇÃO MERCANTIL DO TRÁFICO DE DROGAS
}

A superação do pensamento jurídico clássico, o qual se concretizava a partir de uma operação lógica dedutiva de subsunção do fato à norma, cedeu espaço para uma cultura jurídica pós-positivista, fenômeno necessário na nova ordem social, marcada pela complexidade e pluralidade das relações sociais. Notou-se que o intérprete da norma jurídica, não raro, recorre-se a áreas de conhecimento estranhas ao direito para resolver problemas que não estão pré-solucionados com precisão na norma jurídica. Barroso (2015, p. 346) descreve com exatidão essa mudança de metodologia no estudo da ciência jurídica:

\begin{abstract}
Em uma grande quantidade de situações, a solução para os problemas jurídicos não se encontrará pré-pronta no ordenamento jurídico. Ela terá de ser construída argumentativamente pelo intérprete, com recurso a elementos externos ao sistema normativo. Ele terá de legitimar suas decisões em valores morais e em fins políticos legítimos (...) nesse ambiente em que a solução dos problemas não se encontra integralmente na norma jurídica, surge uma cultura pós-positivista. De fato, se a resposta para os problemas não pode ser encontrada de maneira completa no comando que se encontra a legislação, é preciso procurá-la em outro lugar. E assim, supera-se a separação profunda que o positivismo jurídico havia imposto entre o Direito e outros domínios do conhecimento.
\end{abstract}

É nessa mesma linha de raciocínio que se sugere a análise do problema não somente pela sua faceta jurídica, posto que o tráfico de substâncias entorpecentes é, antes de tudo, uma relação mercantil, sujeita as oscilações e as regras econômicas que regem o mercado. Nela se encontram elementos relacionados ao estudo das Ciência Econômica, tais como: demanda, oferta, procura, disponibilidade do produto, variações do preço etc.

Se por um lado, tem-se o traficante ofertando um determinado produto, no outro, há a demanda por aquisição do objeto da negociação. Este pode ser um usuário ou dependente de drogas ou até mesmo um outro traficante interessado em adquirir o narcótico para revendê-lo e, desse modo, auferir lucro com essa diferença de preço entre as negociações. $\mathrm{O}$ que difere de uma relação comercial comum é basicamente o seu caráter ilícito. Por isso, normalmente é realizado de forma oculta, longe dos organismos estatais de fiscalização e repressão. Tal característica dificulta a obtenção de dados concretos e verdadeiros para a elaboração de estatísticas oficiais, porém não impede a circulação da mercadoria nas diversas 
relações comerciais travadas no país.

O Relatório Mundial sobre Drogas 2014 do Escritório das Nações Unidas sobre Drogas e Crimes divulgado, em Viena, em 26 de junho de 2014, dia internacional contra o abuso de drogas e tráfico ilícito, mostra que o consumo e o tráfico de cocaína aumentaram na América do Sul, particularmente no Brasil. O World Drug Report expõe também que o Brasil é um dos maiores mercados consumidores de maconha do mundo ${ }^{13}$. O Brasil é o segundo maior consumidor de cocaína em relação ao número absoluto de usuários, perdendo apenas para os Estados Unidos. É o que aponta o segundo Levantamento Nacional de Álcool e Drogas, realizado pela Universidade Federal de São Paulo, divulgado em 2012. O levantamento diz que 2,8 milhões de pessoas fizeram o uso da droga e seus derivados no último ano, entre elas 244 mil adolescentes. O II Lenad mostra, ainda, que o Brasil representa $20 \%$ do consumo mundial de cocaína e crack. Em relação a esta última, o país é o maior mercado consumidor do mundo. Um milhão de pessoas utilizaram crack no ano anterior a pesquisa ${ }^{14}$.

Esses dados demonstram a existência de um gigantesco mercado consumidor de drogas que está em ascensão, em contraposição a queda da demanda em outros países. Logo, verifica-se a presença de uma grande e progressiva demanda no Brasil pelo produto.

Recorre-se às lições da Microeconomia, ramo do conhecimento que trata das leis que regem o comportamento econômico de consumidores, produtores e mercados, selecionando os fatores mais importantes, entre os inúmeros capazes de influenciar no fenômeno, sem desconsiderar constantes as variáveis secundárias (VASCONCELLOS, 2002).

O entorpecente é ilícito, mas se encontra disponível no mercado. A ilegalidade do produto conferida por um ordenamento jurídico não é suficiente para retirá-lo da circulação real no mercado do consumo. As transações continuam a ocorrer e, muitas vezes, aumentam de acordo com as leis da economia.

Um ponto que merece destaque é o preço. Nos últimos anos, tem-se notado que o

\footnotetext{
13 Apesar de uso no mundo ter se mantido estável, o relatório também mostra que o consumo e o tráfico de cocaína aumentaram na América do Sul, particularmente no Brasil. O Brasil detém aproximadamente metade da população da América do Sul, o que torna o país vulnerável ao tráfico (devido a sua posição estratégica em relação à Europa) e ao consumo de cocaína, devido a sua grande população urbana, aponta o relatório. Disponível em <http://www.unodc.org/documents/wdr2014/World_Drug_Report_2014_web.pdf>. Acessado em 22 de setembro de 2016.

14 Em publicação recente da Organização Mundial da Saúde, o Brasil foi apontado como uma das nações emergentes onde o consumo de estimulantes como a cocaína - seja na forma intranasal ("pó") ou fumada (crack, merla ou oxi) - está aumentando enquanto na maioria dos países o consumo está diminuindo. Disponível em <http://oglobo.globo.com/arquivos/ii_lenad.pdf >. Acessado em 22 de setembro de 2016.
} 
elemento preço tem decaído. Diga-se, desde logo, que não está se falando aqui das enormes variações de preço existentes entre os centros produtores de droga com os locais de consumo no país, que são responsáveis pelos vultosos lucros dos grandes fornecedores de drogas. Está se tratando, na verdade, é da variação do preço da oferta do produto em um mesmo mercado de consumo (MORAIS, 2005, p. 159):

Em termos gerais, no que se refere às explicações para a reduçãa do preço relativas
à oferta, acreditamos ter havido uma elevação da racionalização das estratégias do
tráfico. Mesmo sendo ilegal, o tráfico é uma atividade mercadológica, assim como
as demais, vai maximizando seus procedimentos, reduzindo seus custos,
adequando seus meios à consecução do seu objetivo: o lucro e/ou a droga (no caso
de pequenos varejistas usuários). Nos países consumidores, a consolidação e a
estabilidade dos pontos de distribuição (não propriamente em termos geográficos),
associadas à definição de fatias dos mercados, possibilitaram maior eficiência ao
negócio.

A Teoria Econômica denomina Lei Geral da Procura como o comportamento dos consumidores que, ao procurarem atender as suas necessidades, compram mercadorias pagando por elas determinados preços. A quantidade procurada de determinado bem varia na razão inversa da variação de seus respectivos preços, mantidas as demais influências constantes (ANDRADE; MADALOZZO, 2003). Portanto, essa lei geral estabelece que maior quantidade de um produto deverá ser comprada a preços mais baixos do que a preços mais altos ou, ainda, toda vez que o preço diminuir, a quantidade procurada deve aumentar e, toda vez que o preço aumentar, a quantidade procurada deve diminuir.

Tem-se notado que, no decorrer do tempo, o entorpecente está sendo mais acessível consumidor. Tome-se, como exemplo a cocaína, cujo preço unitário da cápsula individual pesando cerca de um grama está cada vez mais barato, podendo ser adquirida pelo valor de $\mathrm{R} \$ 20,00$. O que antes era um privilégio de camadas sociais mais favorecidas, hoje pode ser encontrado praticamente em todas as camadas da pirâmide social ${ }^{15}$. O mesmo aconteceu com o crack, cujo valor de uma pequena pedra do entorpecente de apenas $0,25 \mathrm{~g}$ custava $\mathrm{R} \$ 12,00$ e já pode ser encontrada por $\mathrm{R} \$ 5,00^{16}$.

Menciona-se ainda a preferência e o gosto do consumidor a influir no mercado do tráfico. Cita-se que, em Sergipe, a maconha produzida no estrangeiro, principalmente no Paraguai, está progressivamente ocupando o espaço da que é proveniente da região nordestina conhecida como polígono da maconha ${ }^{17}$.

\footnotetext{
${ }^{15}$ Informações prestadas pelo Departamento de Narcóticos do Estado de Sergipe.

${ }^{16} \mathrm{Id}$.

${ }^{17}$ Id.
} 
Essa mudança de produto se refere, em específico, às preferências do consumidor, que tem buscado o entorpecente de "melhor qualidade". A cannabis sativa lineu importada possui índice de delta-nove-tetrahidrocanabinol, seu princípio ativo, bem superior ao produzido no nordeste brasileiro $^{18}$.

Uma vez estabelecida que a substância entorpecente para fins da Lei n. 11.343/2006 encontra-se em plena disponibilidade no mercado, bem como que está mais acessível ao consumidor, vislumbra-se que o aumento da demanda é um possível fator a influenciar na oferta.

\section{CONCLUSÃO}

Foi mencionado que as inovações trazidas pela nova Lei de Tóxicos conferiram um tratamento mais severo ao traficante e menos rigoroso ao consumidor de drogas. A leveza da legislação é tamanha com o usuário e dependente que alguns grandes juristas nacionais defendem a tese de que a Lei n. 11.343/2006 chegou a descriminalizar o porte de droga para uso próprio. Por outro lado, notou-se que dados estatísticos coletados da grande Aracaju revelam um pequeno crescimento do número de pessoas presas por tráfico de drogas entre os anos de 2009 a 2012, na medida em que há um aumento mais significativo da quantidade de substâncias entorpecentes que foram apreendidas no mesmo espaço e período.

Desse modo, percebe-se que a droga, além de estar em plena disponibilidade no mercado, também se apresenta com preços cada vez mais acessíveis ao consumidor. Diante tais fatos, pode-se afirmar que a demanda possui um fator que influencia a oferta, segundo as normas que regem a economia.

Ressalta-se, desde logo, que, em momento algum, foi afirmado ou sugerido neste trabalho que o poder público tem que recrudescer as normas punitivas voltadas para o usuário de entorpecentes. Tampouco foi defendida aqui a tese de criminalização ou descriminalização do porte de drogas para consumo próprio. $\mathrm{Na}$ verdade, pretende-se tão somente chamar a atenção para o fato de que a inserção de normas penais mais flexíveis direcionadas aos usuários de drogas em contraposição a penas mais severas aos ditos

\footnotetext{
${ }^{18}$ A maior parte da maconha consumida no país é proveniente do Paraguai, malgrado também se produza no sertão nordestino brasileiro, conforme consta no relatório de estratégia para o controle internacional de narcóticos, divulgado pelo Departamento de Estado Norte-americano, no ano 2011, destacando o Brasil como o maior consumidor de drogas da América do Sul. Matéria disponível em <http://epocanegocios.globo.com/Revista/Common/0,ERT215965-16418,00.html〉. Acessado em 22 de setembro de 2016.
} 
traficantes não se coaduna plenamente com o espírito de justiça restaurativa, além de ser, de per si, medida insuficiente dotada de ineficácia. Afirmar que houve uma mudança profunda de paradigma, é simplificar por demais o tema.

No entanto, não se omite que as normas jurídicas relacionadas ao novel diploma de tóxicos estabelecem uma atuação diferenciada do poder público e sociedade civil, avançando em muitos temas, todavia, em termos práticos, ainda tem se demonstrado ineficaz, não concretizando o efeito social idealizador de sua concepção, passada quase uma década de sua vigência.

Confirmando a ineficácia da experiência brasileira no enfrentamento ao tráfico de narcóticos, nos padrões atuais, vislumbra-se que o delito em debate é o de maior índice dentre os crimes superpovoam o universo carcerário nacional. O enfretamento à criminalidade deve se modernizar com vistas a obtenção de um controle razoável. A sua eliminação, como pretendiam os defensores do movimento da lei e da ordem e atualmente consubstanciado no populismo vingativo, é mera utopia, até porque o crime é do ponto de vista sociológico algo normal, previsível e necessário para evolução e coesão social (GOMES; MOLINA, 2013, p. 485).

É nesse processo de modernização da Justiça Criminal que surgem as possibilidades de utilização de metodologias restaurativas nos chamados espaços de consenso, os quais dizem respeito à pequena e média criminalidade.

Nota-se que a vigente Lei de Drogas não abarca tão somente crimes graves, vez que, como o próprio tratamento jurídico e diferenciado foi dado aos consumidores de entorpecentes, deslocou o crime de porte para o consumo para o campo dos espaços de consenso $^{19}$. Em contrapartida, a essência mercantil inerente ao comércio ilícito de entorpecentes destaca a importância do consumidor de drogas na própria sobrevivência do tráfico, isto é, ao mesmo tempo em que é tratado juridicamente como criminalidade pequena ou média é também, segundo as lições de microeconomia, ponto de crucial importância para a existência e crescimento do tráfico, um crime bastante grave e danoso.

Desse modo, ainda que prepondere o modelo proibicionista na Lei de Tóxicos

\footnotetext{
${ }^{19}$ A respeito dos espaços de consenso e de conflito, explicita-se que este diz respeito à grande criminalidade enquanto à aquele concerne à média e pequena. $\mathrm{O}$ espaço de consenso está voltado para a ressocialização, podendo, para tanto, mitigar certos direitos e garantias fundamentais, tais como: igualdade de oportunidades, presunção de inocência, ampla defesa e contraditório etc. (GOMES; MOLINA, 2013, p. 486).
} 
brasileira, é possível e até recomendável a implementação de práticas restaurativas nos espaços de consenso, voltadas para a tomada de autoconsciência pelos consumidores de drogas, incutindo um juízo de responsabilidade pessoal e social para com o próximo, pois, como bem ensina Howard Zehr (p. 23, 2012), “a Justiça Restaurativa não se contrapõe necessariamente à justiça retributiva".

A inexistência de uma vítima específica, como ocorre em outros ilícitos, não pode ser um obstáculo intransponível à implementação de práticas restaurativas, vez que, no tráfico, há não somente uma, porém várias vítimas que surgem durante toda a cadeia do seu modus operandi, de crimes direta ou indiretamente vinculados ao comércio de drogas.

Malgrado em linhas teóricas seja um modelo bastante criticado, na prática cotidiana de combate à criminalidade retoma-se frequentemente à Justiça Retributiva como instrumento imediato a atender os reclamos sociais, especialmente em picos de sensação de insegurança. A respeito do tema, quem bem explica a incongruência presente nesses momentos é Jorge da Silva (2008, p. 520), segundo o qual "parece escapar aos arautos desse maniqueísmo é que partem da mesma premissa: de que a criminalidade e a violência são um problema de polícia". O autor continua chamando atenção para "a possibilidade de se operar com uma polícia numerosa, altamente qualificada e eficiente, e simplesmente a criminalidade continuar aumentando".

Nessa toada, a busca pelo enfretamento da criminalidade e de suas consequências nefastas indubitavelmente deve passar pelo combate rigoroso ao tráfico de drogas, onde o consumidor tem papel primordial na proliferação deste tipo de delito. Assim, coadunando com o tratamento jurídico mais brando ao usuário e/ou dependente, propunha-se o incremento e a ampliação de postulados da Justiça Restaurativa como ferramenta de construção de auto responsabilização e conscientização da lesividade das condutas de seus agentes.

\section{REFERÊNCIAS}

ANDRADE, Eduardo; MADALOZZO, Regina. Microeconomia. São Paulo: Publifolha, 2003. 
BARROSO, Luís Roberto. Curso de direito constitucional contemporâneo: os conceitos fundamentais e a construção do novo modelo. 5. ed. São Paulo: Saraiva, 2015.

BRASIL. SUPREMO TRIBUNAL FEDERAL. RE 430.105/RJ. $1^{\text {a }}$ Turma. Rel. Min. Sepúlveda Pertence. DJe 27/04/2007.

. AI 741.072/RJ. $1^{\text {a }}$ Turma. Rel. Min. Dias Toffoli. DJe 25/05/2011.

. HC 110.475/SC. $1^{\text {a }}$ Turma. Rel. Min. Dias Toffoli. DJe 15/03/2012.

BRASIL. SUPERIOR TRIBUNAL DE JUSTIÇA. RHC 7.252/MG. 6a Turma. Rel. Min. Anselmo Santiago. DJ 01/06/1998.

BOYES-WATSON, Carolyn; PRANIS, Kay. No coração da esperança: guia de práticas circulares. trad. Fatima de Bastiani. Porto Alegre: Departamento de Artes Gráficas do TJRS, 2011.

DEPARTAMENTO DE NARCÓTICOS DO ESTADO DE SERGIPE. Estatísticas oficiais. Disponível no órgão pesquisado. Aracaju, 2013.

GOMES, Luiz Flávio; BIANCHINI, Alice; CUNHA, Rogério Sanches. OLIVEIRA, William Terra de Oliveira. Nova lei de drogas comentada. São Paulo, Revista dos Tribunais, 2006, p. 109.

GOMES, Luiz Flávio; MOLINA, Antônio García-Pablos de. Criminologia. 8. ed. v. 5. São Paulo: Revista dos Tribunais, 2012.

ZEHR, Howard. Justiça restaurativa. Trad. Tônia Van Acker. São Paulo: Palas Athena, 2012.

Trocando as lentes: um novo foco sobre o crime e a justiça restaurativa. Trad. Tônia Van Acker. São Paulo: Palas Athena, 2008. 
LEDERACH, John Paul. Transformação de conflitos. trad. Tônia Van Acker. São Paulo: Palas Athena, 2012.

LEVANTAMENTO NACIONAL DE ÁlCOOL E DROGAS (II LENAD), REALIZADO PELA UNIVERSIDADE FEDERAL DE SÃO PAULO (UNIFESP), DIVULGADO EM 2012. Disponível em <http://oglobo.globo.com/arquivos/ii_lenad.pdf >. Acesso em 22 de setembro de 2016.

LIMA, Renato Brasileiro de. Legislação criminal especial comentada. 3.ed. Salvador: Juspodivm, 2015.

MARCÃO, Renato. Tóxicos: lei n. 11.343, de 23 de agosto de 2006, lei de drogas. anotada e interpretada. 9. ed. São Paulo: Saraiva, 2014.

MORAIS, Paulo César de Campos Morais. Drogas e políticas públicas. Belo Horizonte: UFMG, 2005. Tese apresentada como requisito parcial para obtenção do título de Doutor em Ciências Humanas: sociologia e política.

NUCCI, Guilherme de Souza. Leis penais e processuais penais comentadas.3. ed. São Paulo: Revista dos Tribunais, 2008.

BRASIL É O MAIOR CONSUMIDOR DE DROGAS DA AMÉRICA DO SUL, DIZ GOVERNO DOS EUA. Disponível em http://epocanegocios.globo.com/Revista/Common/0,_ERT215965-16418,00.html Acessado em 22 de setembro de 2016.

POPULAÇÃO CARCERÁRIA Disponível em https://www.senado.gov.br/noticias/Jornal/emdiscussao/dependencia-quimica/crack-chama-aatencao-para-dependencia-quimica/populacao-carceraria.aspx Acessado em 22 de setembro de 2016.

POPULAÇÃO CARCERÁRIA BRASILEIRA CHEGA A MAIS DE 622 MIL DETENTOS. Disponível em http://www.justica.gov.br/noticias/populacao-carceraria-brasileirachega-a-mais-de-622-mil-detentos Acesso em 22 de setembro de 2016. 


\section{RELATÓRIO MUNDIAL SOBRE DROGAS 2014 DO ESCRITÓRIO DAS NAÇÕES} UNIDAS SOBRE DROGAS E CRIMES (UNODC). Disponível em http://www.unodc.org/documents/wdr2014/World_Drug_Report_2014_web.pdf. Acesso em 02 abril de 2015.

SILVA, Jorge da. Criminologia crítica: segurança e polícia. 2. ed. Rio de Janeiro: Forense, 2008.

VASCONCELLOS, Marco Antonio Sandoval de. Economia: micro e macro. 3. ed. São Paulo: Atlas, 2002. 